\title{
PULMONARY TUBERCULOSIS MORTALITY IN THE PRINTING AND SHOEMAKING TRADES* HISTORICAL SURVEY, 1881-1931
}

\author{
BY \\ MARGARET CAIRNS $\dagger$ and ALICE STEWART \\ Institute of Social Medicine, Oxford
}

\begin{abstract}
Attention was drawn by Collis (1925) to the fact that, in the Registrar-General's occupational mortality returns for 1911, printers and shoemakers " present the unusual picture of a low general mortality combined with a high phthisis mortality ". Comparison with other trades failed to reveal evidence of predisposing causes such as silicosis, alcoholism, or poverty, but in both occupations the men " worked indoors under circumstances in which individuals are so congregated together as to facilitate the passage of infection from person to person ". Collis suggested, therefore, that the high tuberculosis death rate might be due to crossinfection at work.

The present investigation is based on a study of serial records of mortality (Registrar-General's Decennial Supplements, 1881-1931) and a comparison between these and contemporary working and living conditions. Its purpose is to discover whether printers and shoemakers have always had high tuberculosis death rates and whether cross-infection of fellow-workers has influenced their mortality.
\end{abstract}

\section{MORTAlity ReCORDS (1881-1931)}

Since 1881, the Registrar-General's Decennial Supplements for England and Wales have included an occupational analysis of causes of death. In no two reports is the classification of trades and occupations exactly the same, but in the case of printers and shoemakers, successive alterations have merely involved the subdivision of pre-existing groups. It is therefore possible to calculate comparable rates for each decade. +

In the Decennial Supplement for 1911, which Collis studied, printers and shoemakers had three features in common: a low total death rate, low rates for pneumonia and bronchitis, and high rates for pulmonary tuberculosis. Serial records

\footnotetext{
* One of a series of papers dealing with tuberculosis in industry.

$\dagger$ In receipt of a grant from the Medical Research Council.

$\ddagger$ In the following account, only deaths at ages $25-65$ years are considered. In order to eliminate variations due to changes in the age structure of the two occupational groups, the mortality rates for printers and shoemakers have been standardized. The direct method, based on the 1901 Census, has been used and the rates expressed either as the number of deaths per 10,000 living persons or as a percentage of the standardized rate for all males of the same age at the same date. For purposes of convenience, the latter index is described as the Standardized Mortality Ratio (S.M.R.), although it differs slightly from the original definition of this term (Registrar-General, 1931).
} 
TABLE

Standardized Death Rates and Standardized MortaltTy Ratios (S.M.R.)* MALES AGED 25-65 YEARS (1881-1931)

Tests of significance (see Registrar-General, 1931) show that the pulmonary tuberculosis death rates for factory and home workers in the boot and shoe industry in 1921 and 1931 are significantly different (i.e. $P=$ less than 0.05 ).

\begin{tabular}{|c|c|c|c|c|c|c|}
\hline \multirow[t]{2}{*}{ Group } & \multicolumn{6}{|c|}{$\begin{array}{l}\text { Standardized Death Rates per 10,000 } \\
\text { (Figures in italics=S.M.R.) }\end{array}$} \\
\hline & 1881 & 1891 & 1901 & 1911 & 1921 & 1931 \\
\hline $\begin{array}{l}\text { (a) Mortality from al } \\
\text { Shoemakers } \\
\text { Factory workers } \\
\text { Home workers .. }\end{array}$ & $\begin{array}{l}\text { uses except Pul } \\
\ldots \mid 101 \cdot 887 \\
\ldots \\
. .\end{array}$ & $\begin{array}{l}\text { Imonary Tub } \\
109 \cdot 2 \quad 83\end{array}$ & $\begin{array}{l}\text { erculosis } \\
129 \cdot 7113\end{array}$ & $\begin{array}{ll}84 \cdot 8 & 93 \\
74 \cdot 2 & 81 \dagger \\
88 \cdot 2 & 97 \ddagger\end{array}$ & $\begin{array}{ll}73 \cdot 2 & 94 \\
75 \cdot 2 & 97 \\
71 \cdot 7 & 92\end{array}$ & $\begin{array}{ll}66 \cdot 3 & 93 \\
67 \cdot 4 & 95 \\
65 \cdot 5 & 92\end{array}$ \\
\hline Printers & \begin{tabular}{l|ll} 
& $91 \cdot 3$ & 78
\end{tabular} & $122 \cdot 2 \quad 93$ & $95 \cdot 1 \quad 83$ & $76 \cdot 8 \quad 84$ & $72 \cdot 9 \quad 94$ & $66.0 \quad 93$ \\
\hline All Males &. $.117 \cdot 0 \S 100$ & $131 \cdot 6100$ & $114 \cdot 6100$ & $91 \cdot 4100$ & $77 \cdot 7100$ & $71 \cdot 3100$ \\
\hline $\begin{array}{l}\text { (b) Mortality from } \mathrm{Br} \\
\text { Shoemakers } \ldots \\
\text { Factory workers } \\
\text { Home workers .. }\end{array}$ & $\begin{array}{l}\text { hitis and Pneum } \\
\ldots \\
\ldots\end{array}$ & $\begin{array}{ll}\text { monia } & \\
25 \cdot 7 & 81\end{array}$ & $18 \cdot 1 \quad 87$ & $\begin{array}{rl}12 \cdot 8 & 87 \\
9 \cdot 1 & 62 \dagger \\
14 \cdot 0 & 95 \ddagger\end{array}$ & $\begin{array}{ll}12.0 & 96 \\
12.0 & 96 \\
12.0 & 96\end{array}$ & $\begin{array}{ll}8 \cdot 2 & 94 \\
8 \cdot 1 & 93 \\
8 \cdot 3 & 95\end{array}$ \\
\hline $\begin{array}{ll}\text { Printers } \quad \ldots\end{array}$ & $\begin{array}{l}\text {.. } 20.9 \quad 91\end{array}$ & $28 \cdot 8 \quad 91$ & $15 \cdot 8 \quad 76$ & $11 \cdot 0 \quad 75$ & $11 \cdot 4 \quad 91$ & $8.6 \quad 98$ \\
\hline All Males & .. $23.0 \$ 100$ & $31 \cdot 7 \quad 100$ & $20 \cdot 7100$ & $14 \cdot 7100$ & $12 \cdot 5100$ & $8 \cdot 7100$ \\
\hline $\begin{array}{l}\text { (c) Mortality from } P u \\
\text { Shoemakers } \\
\text { Factory workers } \\
\text { Home workers .. }\end{array}$ & $\begin{array}{l}\text { nary Tuberculo } \\
. .37 .7116 \\
. .\end{array}$ & $41 \cdot 7133$ & $38 \cdot 1 \quad 145$ & $\begin{array}{ll}30.9 & 155 \\
33 \cdot 8 & 169+ \\
29.9 & 150 t\end{array}$ & $\begin{array}{ll}23 \cdot 1 & 150 \\
27.1 & 176 \\
19.9 & 129\end{array}$ & $\begin{array}{ll}19 \cdot 1 & 153 \\
22 \cdot 4 & 179 \\
16 \cdot 4 & 131\end{array}$ \\
\hline Printers & . $68 \cdot 3210$ & $53 \cdot 6171$ & $42 \cdot 7 \quad 163$ & $28 \cdot 1 \quad 141$ & $18 \cdot 6121$ & $15 \cdot 5 \quad 124$ \\
\hline All Males & $32 \cdot 5 \S 100$ & $31 \cdot 4100$ & $26 \cdot 2100$ & $20 \cdot 0 \quad 100$ & $15 \cdot 4100$ & $12 \cdot 5100$ \\
\hline
\end{tabular}

show that the first two points of similarity have existed throughout the period of study (see Table). Except for one figure, the S.M.R. for all causes of death except pulmonary tuberculosis remained below 100 in both groups, while the rate for pneumonia and bronchitis, which is high in occupations with a silica-dust hazard, never rose above $98 . *$

Mortality from pulmonary tuberculosis has not, however, followed the same course in the two groups, and it is only in the 1911 returns that the standardized death rates are at all comparable. Between 1881 and 1931 the pulmonary tuberculosis death rate for all males fell from $32 \cdot 5$ to $12 \cdot 5$. During the same period the rate for printers fell from $68 \cdot 3$ to $15 \cdot 5$, and for shoemakers from $37 \cdot 7$ to $19 \cdot 1$.

The contrast between the two groups is seen more clearly when serial S.M.R.s for pulmonary tuberculosis are compared, as in this case the figure for all males is

\footnotetext{
* For potters, the S.M.R. for pneumonia and bronchitis averaged 256 between 1881 and 1931.
} 
always 100 (see Table and Fig. 1). In the fifty years of records the ratio for printers fell steadily from 210 to 124 . At the beginning of the period it was only 116 for shoemakers; by the end of the century it had risen to 145 ; ten years later it reached a peak of $155, *$ and during the next two decades remained in the region of 150 . This means that the pulmonarytuberculosis death rates for printers and shoemakers respectively fell and rose, in relation to the rate for all males.

The age distribution of deaths from pulmonary tuberculosis has also followed opposite trends. This is shown in Fig. 2 by the ratio

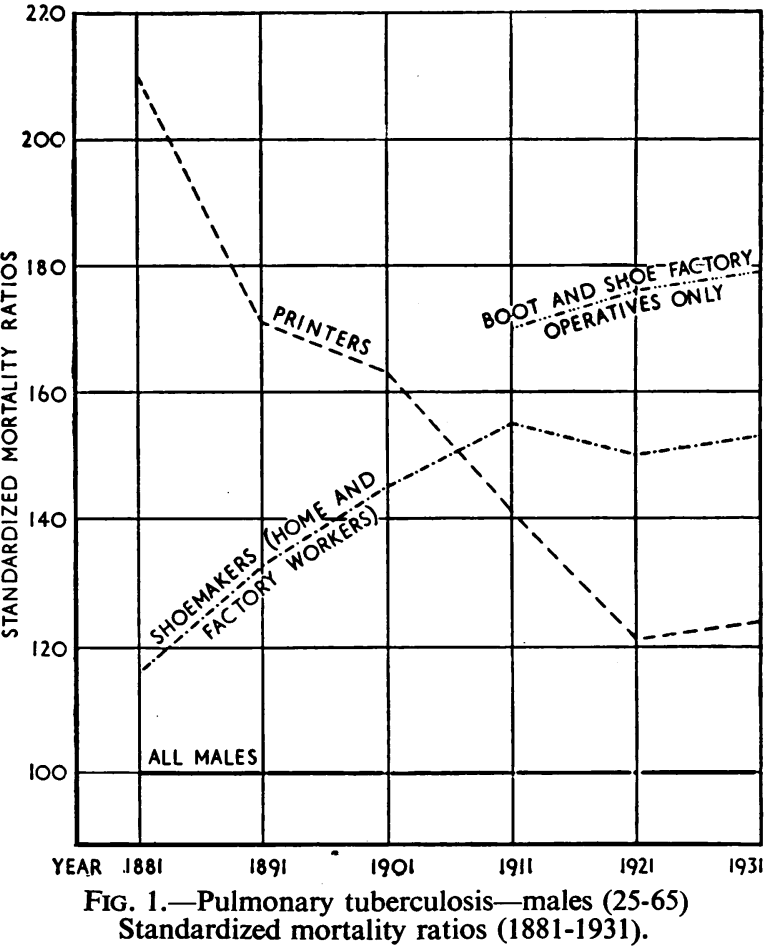
of the death rate at ages 25-44 to that at ages 45-65 in successive decades. During the period of study this ratio fell from 0.96 to 0.84 for all males, and from 1.01 to 0.89 for printers. For shoemakers, however, the ratio rose slightly from $1 \cdot 01$

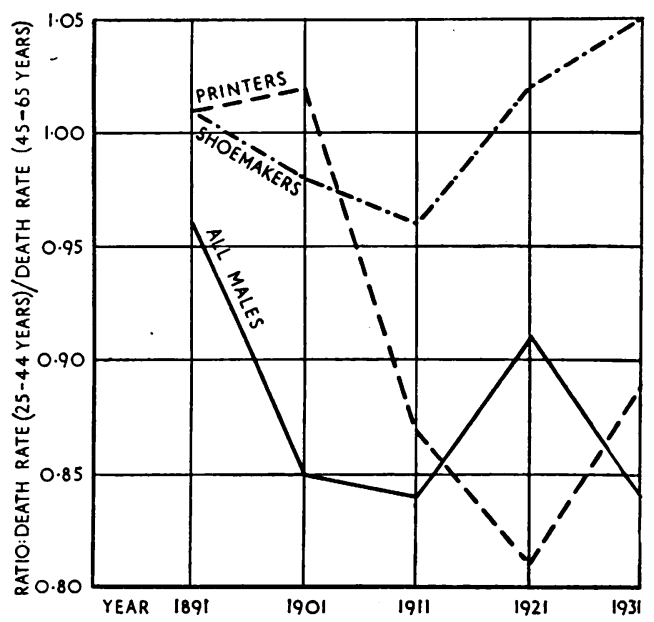

FIG. 2.-Age incidence of mortality from pulmonary tuberculosis (1891-1931). to $1 \cdot 05$. In other words, although in the male population as a whole, and in the printing trade, death from pulmonary tuberculosis has tended to occur progressively later in life, in the shoemaking industry the average age at death has decreased.

Factory and Non-Factory Workers in the Boot and Shoe Industry (19211931).-Printing is essentially a factory occupation and there are no statistics which enable us to

* In 1911 , only six of the fifty skilled manual occupations listed had a higher pulmonary tuberculosis S.M.R. than shoemakers; five of these are now known to have a silica risk. 
compare the death rate of factory workers with that of home workers. In the boot and shoe industry, however, there are two distinct groups of men-those who work in factories (machine operatives) and those who work at home (hand makers and repairers). In the Decennial Supplements for 1921 and 1931 there are separate statistics for these two groups, and these show that the factory section of the industry has a significantly higher tuberculosis death rate than the home section (see Table). Thus, in the two successive decades, the pulmonary tuberculosis S.M.R. is 176 and 179 for " boot and shoe factory operatives " and 129 and 131 for " makers and repairers and non-factory workers".* In both groups, the death rate at ages $16-35$ is exceptionally high, but thereafter the rate remains high only in the factory group. This fact has led the Registrar-General to conclude that some factor other than selective recruitment is influencing the death rate in the factory section of the industry (Registrar-General, 1931). It has since been shown that the industry does recruit a relatively large number of tuberculous subjects and men of poor physique, and also that the incidence of overt pulmonary tuberculosis is higher in large than in small boot and shoe factories (Stewart and Hughes, 1949).

\section{Industrial History of the Printing and Shoemaking Trades}

At the beginning of the 19th century, printers still used hand-operated presses and most of the work was done on small premises which would nowadays be described as " shops " rather than factories. In 1814, however, the steam-operated press - the first major technical advance since the birth of printing in 1470-was introduced. This invention coincided with a greatly increased demand for newspapers and books, and was immediately followed by a succession of new devices for rapid printing. By the middle of the century the trade, which was now housed in relatively large factories, had passed through the preliminary phases of its industrial revolution and assumed a form which it has retained ever since (Stark, 1855; Plomer, 1900).

During this period, other trades concerned with the making of finished goods also adopted the factory system, but shoemaking remained a cottage industry. This exceptional state of affairs was mainly due to technical problems, associated with the intractable nature of leather and the difficulty of devising machinery which could cope with rapid changes in fashion. The displacement of workers by machines in other industries also produced a pool of cheap labour, and this, by mitigating the need for mass production, undoubtedly delayed the industrialization of the boot and shoe industry (Clapham, 1926).

By 1880 , most of the technical problems were solved, but by this time factory regulations had become so stringent that manufacturers often found it more

* In the returns for 1911 there are separate figures for shoemakers in Northamptonshire, Leicestershire, and Lancashire (where there is the maximum concentration of boot and shoe factories), and shoemakers in other regions (most of whom are repairers). This does not constitute a clear-cut distinction between factory and non-factory workers, but the pulmonary tuberculosis S.M.R. is significantly higher in the group known to contain a majority of factory operatives. 
profitable to hire shoemaking machines to outworkers than to build factories. Gradually, however, as mechanization improved, boot and shoe factories increased in size and importance, and by 1911 the old outwork system had virtually disappeared. Since then, the trade has been almost equally divided into two independent sections, one concerned with machine-made shoes, which is essentially a factory occupation, and one with repairing, which is still a home occupation.

\section{Social and Economic Status of Printers and Shoemakers}

The social and economic status of printers has always been high compared with that of other manual workers. Most of the work demands a high standard of education, and language barriers have prevented employers from using foreign labour. Printers have therefore been able to demand good wages, and such is the competition to enter the industry that new recruits are either sons of those already employed or the pick of the schools (Llewellyn Smith, 1930).

Printers are still relatively well paid, but the gap between them and less privileged men has gradually narrowed (Ministry of Labour Gazette, 1926-1946). The introduction of compulsory education has improved the status of other manual workers, the level of technical proficiency required in other trades has risen, and certain printing operations which formerly demanded well-educated workers have become mechanized.

The shoe trade was not involved in the early phase of the Industrial Revolution, and until shoemakers moved into factories they did not benefit by 19th-century labour reform which was wholly concerned with factory workers. They did not, however, escape the adverse effects of the growing divorce between capital and labour. As this developed, shoemaking contracts tended to be relayed (without equivalent profits) through a series of middlemen down to the workers themselves, who had to be content with irregular employment and day wages: a system openly described as "sweated labour". Outworkers did not succeed in obtaining legal protection until 1912 (Trade Boards Act), and Booth and others (1892) found that shoemakers had poorer living conditions than any other group of workers except costermongers and casual labourers.

Against this background of subjugation and distress the migration of shoemakers into factories stands out, not as a social evil, but as a remedy for evils already present. Arlidge (1892), in a discussion of occupational diseases, commented on the unhealthy appearance of shoemakers, and added: "It will be interesting to learn what changes for the better the adoption of machines and the extension of the factory system to the trade have wrought in the health history of shoemakers." The change was also welcomed by the Factory Inspectors, and in 1890 we find the Inspector for the Midlands writing as follows:

Several large new (boot and shoe) factories have been opened during the past year, the tendericy being to have all the workers on the premises instead of giving the work to be done at the homes of the workers. I cannot but rejoice at this tendency, for the substitution of spacious, clean, and well-ventilated rooms for the 
miserable dens at the backs of cottages must be for the benefit of the health of the workers. . . . The hours of work, too, in " factories" will be more regular and more easily regulated than in the small "workshops" in private houses.

Economically also the change was wholly for the better, coinciding as it did with the culminating phase of the 19th-century Trade Union movement. In 1895, a settlement between boot and shoe operatives and employers was achieved, wages were revised, a graduated scale of payment was established, and hours of work were fixed. At the same time, a mutual trust fund was formed, which is still regarded as a model for the maintenance of industrial peace and is probably the most important single factor responsible for the absence of any major trade disputes in the boot and shoe industry during the present century (Brunner, 1949).

From this brief account it is evident that during the period of mortality records (1881-1931) working conditions in the printing trade were relatively stable. Wages certainly increased and living conditions improved, but although printers continued to enjoy many privileges, the difference in economic status between them and other manual workers steadily diminished. In spite of this, the tuberculosis death rate for printers declined more rapidly than the rate for all males.

For the boot and shoe industry, the years between 1881 and 1911 were ones of profound change. During this period the old-fashioned cordwainer who worked at home was replaced by the modern factory operative; but owing to the fact that the change-over from outwork to the factory system occurred late and was preceded by more than fifty years of factory reform, it did not lower the standard of living

of the workers. On the contrary, by bringing to an end a vicious system of irregular employment and underpayment, it brought about a marked improvement in their social and economic status. Nevertheless, the pulmonary tuberculosis death rate for shoemakers rose, relative to the national rate.

\section{Discussion}

The main difficulty in isolating the role of cross-infection in the development of pulmonary tuberculosis is that, in most communities, the degree of crowding is a measure not only of opportunities for cross-infection but also of a number of other factors which influence resistance to disease. Thus, overcrowding in the home is usually accompanied by poverty, malnutrition, and faulty hygiene. The effect of these on lowering resistance is shown by the fact that, in communities defined by region, a high tuberculosis mortality is accompanied by a high mortality from other causes of death. In communities defined by occupation, however, crowding at work is not necessarily associated with poverty, and it is at least theoretically possible to isolate the role of cross-infection.

The very fact that the high tuberculosis mortality in the printing and shoemaking trades was not associated with a high general mortality provided Collis with a priori evidence for the operation of infection. This observation is now supported by other evidence. In the present investigation the general resistance 
to disease of printers and shoemakers has been deduced $(i)$ from their mortality from diseases other than tuberculosis, and (ii) from general information about their social and economic conditions. The opposite trends of tuberculosis mortality appear to bear no relation to either of these.

Thus, at the climax of the outwork system-an evil compounded of insecurity, poor living and working conditions, and physical overstrain-mortality from pulmonary tuberculosis among shoemakers was far lower than that among printers who then represented one of the most prosperous groups of manual workers. The subsequent rise in the relative phthisis mortality of shoemakers (1881-1911) occurred at a time when the adoption of the factory system was creating a steady improvement in the standard of living of shoemakers. There was no comparable improvement in living conditions of printers during this period, and yet their relative mortality fell until, in 1911, it was lower than that of shoemakers. These points may be tabulated as follows:

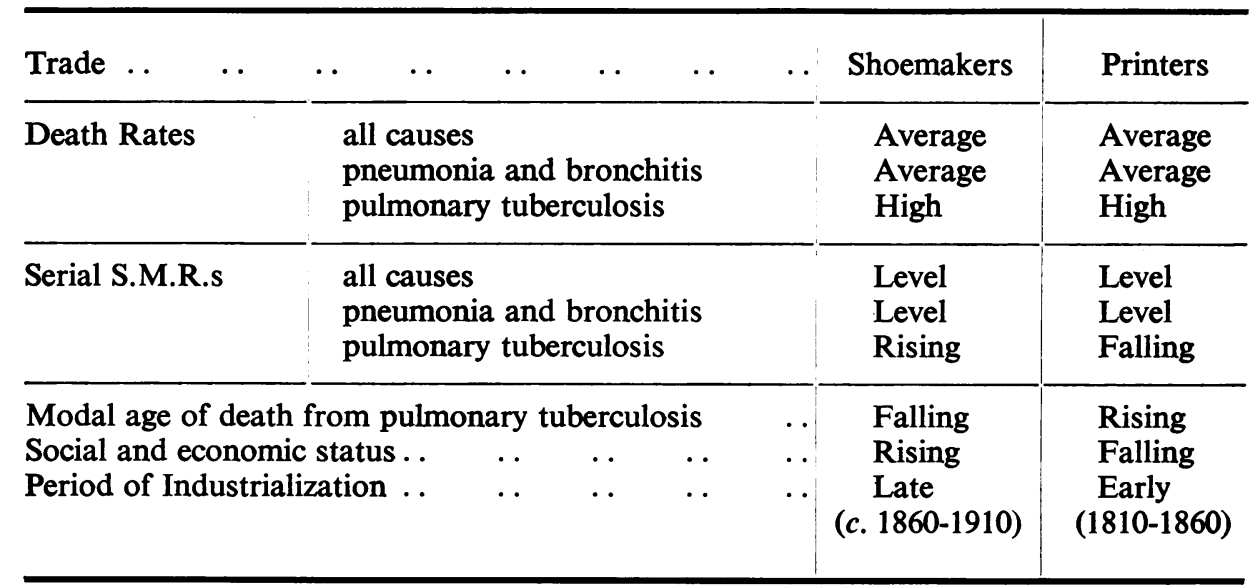

The contrasting trends of the tuberculosis mortality figures cannot therefore be related to the changing social and economic conditions in the two industries. Since the other major difference between the two occupations is the date of their industrialization, it is possible that this provides a satisfactory explanation.

During the period for which there are records, shoemakers progressively changed from working at home to working in factories, and their mortality from pulmonary tuberculosis, compared with that of the nation, rose. The most likely explanation of this is that factory life provided increased opportunities for crossinfection. This suggestion is supported by two independent observations. First, factory operatives have a higher tuberculosis death rate than home workers, and secondly mass radiography has revealed a positive correlation between factory size (i.e. number of workers) and the incidence of overt pulmonary tuberculosis (Stewart and Hughes, 1949). The latter finding, which was the reverse of what might be expected from factory inspectors' reports (Board of Trade Working Party Report, 
1946), is now supported by notification data from Northampton and Leicester, and there seems to be little doubt that the size of the working unit does influence tuberculosis morbidity rates (Stewart and others, 1950).

But if the first effect of increased exposure to infection is to increase the incidence of an infectious disease, the long-term effect is to increase resistance. This is especially true in the case of occupational groups which are, by definition, composed of men over the age of 24 years and are known to have a strong family tradition. In such communities, resistance to tuberculosis must be influenced by the amount of overt disease in the previous generation of workers, since this affects the "childhood" infection rate and the number of persons who die or become Mantouxpositive before reaching the age of 25 years.*

We suggest, therefore, that

(a) the high pulmonary tuberculosis death rates in the printing and shoe trades are due, in the first instance, to selective recruitment;

(b) the rapid fall in the tuberculosis death rate for printers since 1881 is due to the late effects of increased exposure to infection during the early years of industrialization (c. 1810-1860);

(c) the rise in the relative tuberculosis death rate for shoemakers between 1881 and 1911 is due to the early effects of increased exposure to infection at work.

In other words, the records for printers and shoemakers represent the descending and ascending phases respectively of two slow-motion epidemics in trades which recruit an exceptionally large number of tuberculous subjects, one epidemic having been initiated in the first and the other in the second half of the 19th century.

The changing age incidence of death from tuberculosis in the two populations supports this hypothesis. Since 1891, deaths from pulmonary tuberculosis have tended to occur progressively later among males in England and Wales; yet in spite of this there was, during the period when the disease proved increasingly fatal to them, a slight fall in the average age at death among shoemakers. In the printing trade, on the other hand, there was a pronounced movement in the opposite direction. This again suggests that during the period of records shoemakers have been more, and printers less, prone to contract tuberculosis when exposed to infection than the average working man.

If this theory is correct, an epidemic of tuberculosis in a partially closed community should last approximately a hundred years. This is, in fact, the estimated duration of the rise and fall of the death rate which follows the introduction of the disease into a previously healthy community. Burnet (1948) says:

* An alternative explanation, namely that printers and shoemakers are recruited from families which are unduly susceptible to tuberculosis, was considered, but in view of the following observations it has been rejected. In a group of 2,260 factory workers in Northamptonshire (shoemakers and others) the incidence of notified cases of tuberculosis was approximately the same among shoemakers whose parents worked in other trades as amongst those whose parents were also shoemakers $(1.2$ and 1.4 per cent. respectively). Workers in other occupations had significantly lower rates, but again there was no difference between those whose parents were shoemakers and those whose parents were not $(0.6$ per cent in both groups) (Stewart and others, 1950). 
It has been calculated on the basis of experience in Mauritius that it takes about a hundred years of life in a tuberculous environment to weed out susceptible strains to a level which allows a tolerable equilibrium between man and the tubercle bacillus.

This quotation admirably describes the experience which industrialization inflicts on workers in occupations where the work is not heavy enough to discourage the recruitment of persons suffering from chronic tuberculosis.

The hypothesis advanced here is difficult to test, since it rests largely on a retrospective study. It is, however, supported by Smith (1863) who stated (admittedly on crude data) that the tuberculosis mortality rate for printers in London between 1851 and 1861 was " nearly double that of the ordinary community" (i.e. of persons over 20 years of age living in London) in 1851; for this implies that the downward trend recorded since 1881 would not have been a feature of earlier records, had they existed. It is also possible that future records for shoemakers will produce one more missing link in the argument and justify our impression that this industry has already entered on the declining phase of its epidemic.

\section{SUMMARY}

(1) During the industrialization of the boot and shoe industry in England (1881-1910), when the proportion of factory to home workers was increasing, shoemakers showed a rising mortality from pulmonary tuberculosis compared with the rate in the male population as a whole. Over the same period, their death rates from all other causes remained low (S.M.R. below 100), and their social and economic conditions improved.

(2) Records for 1921 and 1931 show that the mortality from pulmonary tuberculosis in the shoe trade was significantly higher among factory operatives than among home workers.

(3) The only explanation that we have been able to offer for $(a)$ the different rates for factory and home workers, and $(b)$ the relative rise in mortality which accompanied the concentration of home workers into factories, is that the aggregation of men, some of whom are carriers, favours the spread of tuberculosis. This is supported by a study of tuberculosis morbidity rates in boot and shoe factories, which has revealed a correlation between factory population and incidence of overt pulmonary tuberculosis.

(4) Seventy years ago, the death rate from pulmonary tuberculosis among printers was over twice the rate for all males of working age. Since then, the rate has fallen relatively rapidly, and in 1931 it was only 24 per cent. above the rate for all males of working age. Throughout the period, their general mortality has been low.

(5) The printing trade was industrialized in the first half of the 19th century and has altered little since then. There has not been so much improvement in the social and economic status of printers as in that of other manual workers.

(6) It is recalled that the introduction of tuberculosis into a primitive community previously exempt from the disease has been known to provoke an epidemic 
lasting a hundred years. The industrialization of trades where the work is light enough to permit the presence of chronic carriers may provoke similar slowmotion epidemics. Since the printing trade was industrialized some fifty years before the shoe trade, we have suggested that the tuberculosis mortality trends for printers and shoemakers during the fifty years of records represent respectively the declining and ascending phases of two such epidemics.

\section{REFERENCES}

Arlidge, J. T. (1892). “The Hygiene, Diseases and Mortality of Occupations.” Percival, London. Board of Trade (1946) Working Party Reports: Boots and Shoes. H.M.S.O., London.

Booth, Charles, ed. (1892). "Life and Labour of the People in London." 2nd edit., Industry, 2, 3, and 5. Macmillan, London.

Brunner, E. (1949). Oxford Economics Papers, n.s. 1, 247.

Burnet, F. M. (1948). Med. J. Aust., 1, 57.

Clapham, J. H. (1926). " An Economic History of Modern Britain." University Press, Cambridge.

Collis, E. L. (1925). J. State Med., 33, 101.

Home Office. H.M. Factory Inspectors' Report to the Home Secretary (1890). Parliamentary Papers, England, xix.

Llewellyn Smith, H., ed. (1930). "The New Survey of London Life and Labour ", vol. 5, chap. 6. London School of Economics.

Ministry of Labour Gazette (1926-1946). H.M.S.O., London.

Plomer, H. R. (1900). " A Short History of English Printing, 1476-1898." Kegan Paul, London.

Registrar-General (1881-1931). Decennial Supplements for England and Wales: Occupational Mortality. H.M.S.O., London.

Smith, E. (1863). In Sixth Report of the Medical Officer of the Privy Council, vi, 403. H.M.S.O.

Stark, Adam (1855). " Printing: its Antecedents, Origin, History and Results." Longmans, London. Stewart, A. M. (1950). Unpublished work.

- 